\title{
The Relationship between Simultaneous Interpreters' Speed of Speaking in Persian and the Quality of their Interpreting: A Gender Perspective
}

\author{
Poorandokht Hasanshahi ${ }^{1} \&$ Mohsen Shahrokhi ${ }^{1}$ \\ ${ }^{1}$ Department of English, Shahreza Branch, Islamic Azad University, Shahreza, Isfahan, Iran \\ Correspondence: Mohsen Shahrokhi (Ph.D.), Department of English, Shahreza Branch, Islamic Azad University, \\ Shahreza, Isfahan, Iran. Tel: 98-31-5350-2501. E-mail: shahrokhi1651@yahoo.com
}

Received: March 13, 2016 Accepted: April 30, 2016 Online Published: May 25, 2016

doi:10.5539/ijel.v6n3p11 URL: http://dx.doi.org/10.5539/ijel.v6n3p11

\begin{abstract}
This research sought to investigate the relationship between two complex ways of communicating, i.e., speaking and simultaneous interpreting which manifest complex linguistic and neurological processes undertaken with an incredible speed in the brain. The current study aimed at testing whether there was any significant difference between male and female interpreters' quality of simultaneous interpretation in relation to their speed of speaking in their native language. To this end, a number of thirty participants were chosen based on their proficiency level out of fifty simultaneous interpreters. To test the research hypotheses both descriptive and inferential statistics were used. The results revealed that there was not any significant difference between male and female interpreters with regard to their quality of simultaneous interpretation. Moreover, with regard to the speed of speaking there was a difference between genders; finally, there was no association between interpreters' speed of speaking and their quality of interpretation.
\end{abstract}

Keywords: interpreting, simultaneous interpretation, native language, quality, gender

\section{Background}

By nature, oral translation is a challenging and demanding task because two or more divergent languages are involved (Dukate, 2007). Interpretation makes the oral communication possible for people who come from different speech communities. In an interpretation process, the interpreter serves as a linking medium that transfers the content of communication as thoroughly and faithfully as possible. Interpretation, however, is not a verbatim (word-for word) process-contrary to popular belief.

Phelan (2001) stated that in order for interpreters to handle a successful job, they should possess good short term and long term memories. The short term memory helps retain what is heard and the long term memory is used to contextualize what is heard. In addition to a good memory, both adequate concentrating and analyzing skills are also required as confirmed by Gile (1995). In an attempt to account for the complexities of interpretation, Gile (1990) proposed his famous 'Effort Mode' in which he asserted that overcoming the challenges of interpretation requires the interpreter to employ a series of skillful techniques and strategies. Gile's model is based on the concept of processing capacity in which the interpretation is thought of as a process including different simultaneous mental functions that require great processing capacities.

Interpreting could be performed simultaneously or consecutively. Time constraints most often leave no opportunity for the interpreter to refer to written resources available to translators (Morris, 2000). This challenge requires the advance preparation all the more essential for an interpreter.

Another challenge for the interpreter is the high speed involved in receiving, understanding, managing, and reconstructing processes of interpretation (Lamber \& Moser-Mercer, 1995). While translators may render between two-thousand and three-thousand words daily, an interpreter may have to take care of some one-hundred-fifty words per minute.

Therefore, the scientific requirements in addition to critical verbal competence do not let interpretation to be a suitable job for everybody. The interpreters have to be knowledgeable and competent enough to handle their job successfully. In addition to scientific requirement and other critical competences, it seems biological differences 
may have an impact on the process of interpretation because it goes without saying that males and females are suitable for different jobs. Does the challenging nature of interpretation call for a specific gender to handle it? Is this a fact which should be taken into account also?

\subsection{Statement of the Problem}

There are five interwoven steps through which simultaneous interpretation is obtained (Setton, 2002). First, receiving the sender's message in the source language; second, encoding the received message; third, understanding the message; fourth, decoding the understood message into the target language; and finally, conveying it in the target language. Taking the multifaceted nature of simultaneous interpretation into account, the past studies conducted in this area has failed to provide a precise account of what is occurring when simultaneous interpretation is performed. The precise explanation of simultaneous interpretation is very difficult because of the influence of a number of recognized and unrecognized factors. Simultaneous interpretation includes three main language skills namely, listening, comprehending, and speaking. The intricacies of each of these three skills have led to conducting many studies and findings many issues that still call for further studies. Brain, for example, and its functions in the listening, comprehending, and speaking are among the most complicated and unknown titles of research (Peer, 2000).

Simultaneous interpretation as a task influenced by mental skills and social activities as it includes dealing with two languages belonging to two communities cannot be studied as a single task. None of the social and mental issues involved in simultaneous interpretation could be studied separately as any attempt made to untie the interwoven dissimilar issues of simultaneous interpretation would be inefficient. Time as one of the important issues is an additional factor influencing the nature of simultaneous interpretation (Kaye, 2008). Time constraints and pressures should be taken into consideration as one of the contextual variables that influences the senses much so that interpretation and translation are considered horses of different colors from a technical point of view.

Reviewing the literature includes many studies in which interpretation has been investigated from different perspective to find the relationship among the issues involved in simultaneous interpretation, e.g., quality of interpretation (Kalina, 2002; Kopczynsky, 1994; Marrone, 1993; Moser-Mercer, 1996), time constraint, and speed of speaking. However, as for the relationship between quality of interpretation and speed of speaking in relation to time constraints, previous studies have come up with many inconsistent results. For example, Shirinzade (2013) has discovered that there is a positive relationship between the simultaneous interpreters' speed of speaking in Persian and their quality of interpreting into Persian, but Hoseinzade (2006) has found there is no significant correlation between simultaneous interpreters' speed of speaking in Farsi and the quality of their simultaneous interpreting from English into Farsi. Therefore, the main concern in this research was to reinstate whether there is any significant relationship between simultaneous interpreters' speed of speaking in their native language, and the quality of their simultaneous interpreting. Moreover, the study intends to check whether there is any significant difference between male and female interpreters' quality of simultaneous interpretation in relation to their speed of speaking in their native language.

\subsection{Objectives and Scope of the Study}

Differences in behavior between genders must, in some way, be a reflection of systematic differences between the brains of males and females. Such differences certainly exist, but drawing inferences from them is not as easy as it may appear.

The main issue that this study addressed was that whether there is any significant difference between male and female interpreters' quality of simultaneous interpretation from English into Persian in relation to their speed of speaking in their native language that is Persian. Another aim of the current research was to investigate the relationship between interpreters' quality of simultaneous interpretation and their speed of speaking in their native language.

\subsection{Research Questions}

As to what was explained above as the aims of this study, the following research questions are raised:

(1). Is there any significant difference between male and female interpreters' quality of simultaneous interpretation?

(2). Is there any significant difference between male and female interpreters' speed of speaking in their native language?

(3). Is there any significant relationship between interpreters' quality of simultaneous interpretation and their 
speed of speaking in their native language?

\subsection{Research Hypotheses}

Concerning the research questions mentioned above, the subsequent null hypotheses were formulated to be tested in the present study.

H01. There is not any significant difference between male and female interpreters' quality of simultaneous interpretation.

H02.There is not any significant difference between male and female interpreters' speed of speaking in their native language.

H03.There is not any significant relationship between interpreters' quality of simultaneous interpretation and their speed of speaking in their native language.

\subsection{Significance of the Study}

The significance of this research stems from the fact that very little research, at least in Iran, has tackled problems that interpreters encounter and strategies they use in interpreting. Additionally, this study is based on real-time interpreting, but to the best of the researchers' knowledge, very few real-time studies have been carried out in interpreting so far. The research underway is also different from previous ones with respect to its sample, method and materials. Although, translation is a long-lasting task used in communication, there are few studies that empirically address different aspects of translation and interpretation. This study investigated one of the untouched aspects of interpretation, which is gender, and its relationship with quality of interpretation. Hopefully, students of translation and interpreting, interpreters and teachers of interpreting employ the findings of this study for better understanding of interpreting.

\section{Methodology}

\subsection{Participants}

The sample of this study included both female and male interpreters. It consisted of two groups, each was of fifteen participants. They were at upper intermediate general English proficiency based on their performance on Quick Placement Test (QPT). All of the subjects were native speakers of Persian. Regarding the age range, the participants were between twenty three and thirty years of age.

\subsection{Instruments}

The instruments for this study comprised of four sets: QPT, Oral test of simultaneous translation, Persian text, digital voice recorder, and a stop watch.

In order to control for the proficiency factor, there was a need to homogenize the participants according to their level of L2 proficiency. To do so the Quick Placement Test was used to select the upper intermediate group. The test consisted of 60 questions. All of the questions were multiple choices. Fifty multiple choice questions were related to the knowledge of vocabulary and 10 multiple choice questions which assessed the participants' knowledge of grammar and their time was 30 minutes.

Moreover, an oral translation test was used. It required spontaneous use of formal language. Therefore, an oral translation test was designed to evaluate the quality of simultaneous interpreters' work. The reading text was chosen from one of Cambridge IELTS exams and it was about 'The Significance of sports', it included 3 paragraphs and 10 sentences.

In order to assess the speed of speaking, a text of Persian language was chosen from the internet. It was about 'The Significance of sports', it included 3 paragraphs and 14 sentences.

Another instrument used for data collection was a digital voice recorder. It was a handheld device designed to record voice and sound with superior sound recording and playback to record the translation of the participant. A Stop Watch was also used to check the time of interpreting and to assess the speed of speaking in native language, i.e., Persian.

\subsection{Data Collection Procedure}

At the beginning in order to select the required number of student participants, the QPT was administrated to 100 master university students, majoring translation from Islamic Azad University of Shahreza, Islamic Azad University of Khorasgan and Islamic Azad University of Shiraz. Their time was 30 minutes. Then 30 students whose scores fall between 40-47 (upper intermediate level according to the test scale) were chosen, 15 males and 15 females. 
In the next stage the oral test of simultaneous translation was administrated to assess their interpreter's interpretation. The researchers offered all the interpreters the same materials for interpreting. The text was about 'The Significance of sports'. Sentences were read by one of the researchers one by one. Interpreters listened to the speaker and then rendered their interpreting. All the interpretations were simultaneously recorded. A research assistant accompanied the researchers to record interpretations with a digital voice recorder. Every simultaneous interpreter's interpretation was then transcribed by the researchers to be studied.

After that for assessing the speed of speaking, the text in Persian language was given to the interpreters to read with the highest speed they could. Their times from start to the end were recorded with a stop watch.

Transcribing the interpretation was carefully performed not to even overlook one word. The researchers frequently had to rerun an utterance a number of times for recognizing the words. The voices were recorded with a digital voice recorder and then the number of words spoken in each second was measured based on the scale of word per second (wps).

Finally, evaluating the quality of interpretation was done based on Kurz' criteria.

\subsection{Data Analysis Framework}

For analyzing the quality of interpretation and in order to increase the reliability of data analysis, three raters were trained to analyze the data based on Kurz's (2001) criteria. The gathered data were analyzed based on Kurz's model with slight modifications. According to his model for the quality of interpretation, there were seven criteria: fluency of delivery, logical cohesion of utterance, sense consistency with original message, completeness of interpretation, correct grammatical usage, use of correct terminology, and pleasant voice. The factor of 'voice' was deleted since the quality of one's voice is a biological factor which is not manageable by people. One might be graded as good due to his/her voice quality by some people while he/she may not be graded as good by some others. What was instead replaced here was 'style' which was a very crucial factor. Style refers to the extent the formality of language is taken into account in interpreting.

Kurz's (2001) model is explained as follows:

- Fluency of delivery implies performing an energetic discussion with less uncertainty, pauses, and unbalanced abnormal rhythm.

- Logical cohesion is nearly the same as coherence in linguistics. What the interpreter does must be coherent as a whole. Coherence includes the extent to which the element of the discourse, that is, the authentic words we read or hear hang together jointly in a logical string. Therefore, in order for the interpreters to have a logical well-tied interpretation they should be competent in utilizing cohesive ties wherever they are required.

- Sense consistency refers to similarity of the interpreted meaning with the source language sense. That is to say the conveyed message should be consistent with the source message when the interpreters should convey the source message into the target language.

- Completeness of interpretation stresses that the conveyed message by the interpreter should be as informative as the source language and no pieces of information should be left unnoticed by the interpreter. The clearness and transparency should not be ignored and incomplete interpreting is not respected.

- Correct grammatical interpretation is emphasized because it is directly associated with the standard grammar rules which are utilized in the target language.

- Correct terminology refers to the correct word choice as far as technical words are concerned.

- Style implies the formality of the language.

Table 1. Criteria for simultaneous interpretation quality assessment

\begin{tabular}{llll}
\hline Criteria & Score & Coefficient & Total score \\
\hline Fluency & 4 & 2 & 8 \\
Logical cohesion & 4 & 1 & 4 \\
Sense consistency & 4 & 3 & 12 \\
Completeness & 4 & 2 & 8 \\
Grammar & 4 & 2 & 8 \\
Terminology & 4 & 3 & 12 \\
Style & 4 & 3 & 8 \\
Total & $\mathbf{2 8}$ & $\mathbf{1 5}$ & $\mathbf{6 0}$ \\
\hline
\end{tabular}


Each factor had four grades but their coefficient was different from another one based on their importance. Graded as the highest, one was awarded 60 points which was later converted to a scale of 0-20.

After collecting the required data, participants' productions were coded using the assessment criteria for the of quality simultaneous interpretation as discussed above. Afterwards, a number of statistical tests were performed to check the research hypotheses. The minimum alpha for confirmation of the research hypotheses was .05 . Statistical Package for Social Sciences (SPSS) version 22.0 was used to perform all the statistical analyses in this study.

An independent samples t-test was carried out on males and females' quality scores to see if the gender had any effect on the participants' interpretation quality. Additionally, another independent samples t-test was conducted on the speed scores to see for which gender group differences are probably significant. Finally, to check the third hypothesis, Pearson product-moment correlation coefficients were run to investigate the correlation between the subjects' quality of simultaneous interpretation and their speed of speaking.

\section{Data Analysis and Results}

\subsection{The Effect of Gender on the Interpreters' Quality of Simultaneous Interpretation}

The first research question addressed the effect of gender on interpreters' quality of simultaneous interpretation. In response to this question, the following hypothesis one was formulated:

Hypothesis 1: There is not any significant difference between male and female interpreters' quality of simultaneous interpretation.

The first hypothesis of the study was tested by running an independent samples t-test. As it is customary in humanities, an alpha level of .05 was set for testing the hypothesis. The descriptive statistics of the male and female participants were calculated prior to running the t-test as reported in Table 2.

Table 2. Descriptive statistics for the quality of simultaneous interpretation

\begin{tabular}{llllll}
\hline & Gender & N & Mean & Std. Deviation & Std. Error Mean \\
\hline Quality & Male & 15 & 41.07 & 3.955 & 1.021 \\
& Female & 15 & 41.33 & 3.266 & .843 \\
\hline
\end{tabular}

Table 2 shows that the interpretation scores are not equivalent for the two groups. The mean score of the female group $(M=41.33)$ is slightly higher that of the male group $(M=41.07)$. In order to show the differences more clearly findings are also illustrated in Figure 1. Although the mean score of the two tests are slightly different, it is not clear whether this difference is statistically significant or not. Therefore, independent samples t-tests were carried out on the scores of the quality of simultaneous interpretation across gender (see Table 3).

Table 3. Independent samples t-test of the quality of simultaneous interpretation

\begin{tabular}{|c|c|c|c|c|c|c|c|c|c|c|}
\hline & & \multicolumn{3}{|c|}{$\begin{array}{l}\text { Levene's Test for } \\
\text { Equality of } \\
\text { Variances }\end{array}$} & \multicolumn{4}{|c|}{ t-test for Equality of Means } & & \\
\hline & & F & Sig. & $\mathrm{t}$ & Df & $\begin{array}{l}\text { Sig. } \\
\text { (2-tailed) }\end{array}$ & $\begin{array}{l}\text { Mean } \\
\text { Difference }\end{array}$ & $\begin{array}{l}\text { Std. Error } \\
\text { Difference }\end{array}$ & \multicolumn{2}{|c|}{$\begin{array}{l}95 \% \text { Confidence Interval } \\
\text { of the Difference }\end{array}$} \\
\hline & & & & & & & & & Lower & Upper \\
\hline \multirow[t]{2}{*}{ Speed } & Equal variances assumed & .182 & .673 & -.201 & 28 & .842 & -.267 & 1.324 & -2.979 & 2.446 \\
\hline & $\begin{array}{l}\text { Equal variances not } \\
\text { assumed }\end{array}$ & & & -.201 & 27.034 & .842 & -.267 & 1.324 & -2.984 & 2.450 \\
\hline
\end{tabular}

T-test results, reported in Table 3, reveal that there is not any statistically significant difference between male and female interpreters with regards to their quality of simultaneous interpretation $(t(28)=-.201, p=.842$, two-tailed). This finding suggests that gender does not have any effect on Iranian interpreters' quality of simultaneous interpretations.

Based on the obtained results, therefore, the first null hypothesis stating that there is not any significant difference between male and female interpreters' quality of simultaneous interpretation is confirmed. 


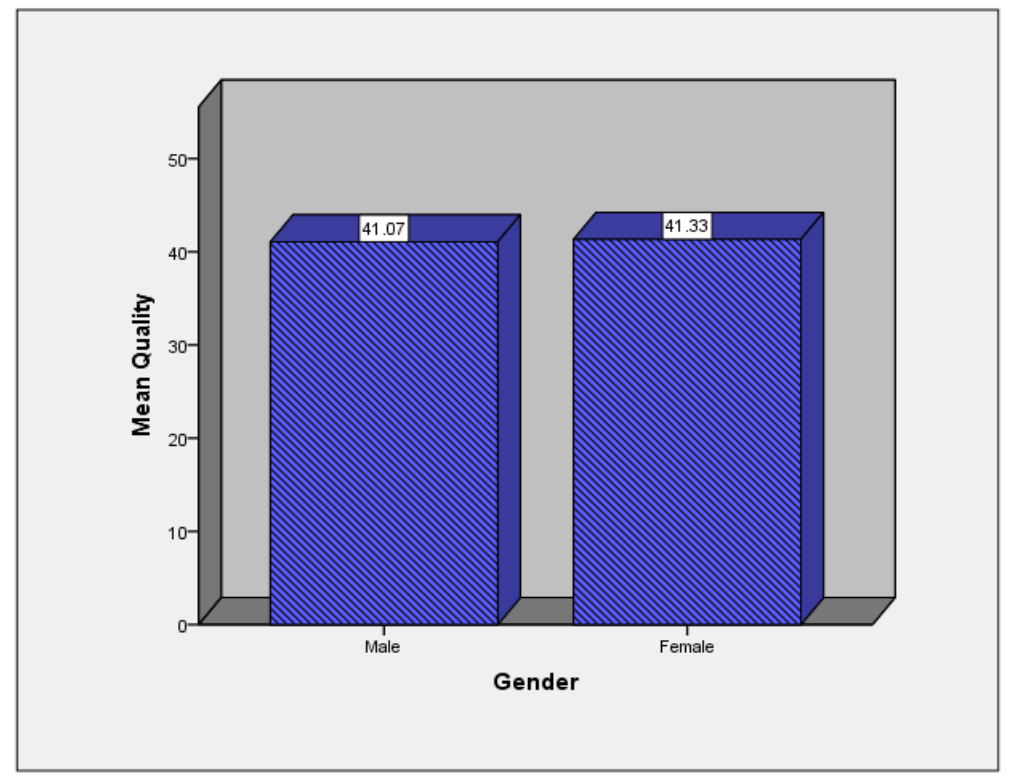

Figure 1. Quality of simultaneous interpretation among male and female interpreters

\subsection{The Effect of Gender on the Interpreters'Speed of Speaking}

The second research question tried to investigate if gender has any effect on interpreters' speed of speaking in their native language (i.e., Persian). Accordingly, the following null hypothesis was formulated to be tested.

Hypothesis 2: There is not any significant difference between male and female interpreters' speed of speaking in their native language.

To test the above hypothesis, the speed scores of male and female participants were subjected to another independent samples t-test. As displayed in Table 4, at first the descriptive data of male and female interpreters were calculated.

Table 4. Descriptive statistics for the speed of speaking

\begin{tabular}{llllll}
\hline & Gender & N & Mean & Std. Deviation & Std. Error Mean \\
\hline \multirow{2}{*}{ Speed } & Male & 15 & 167.60 & 30.052 & 7.759 \\
& Female & 15 & 205.27 & 29.776 & 7.688 \\
\hline
\end{tabular}

As presented in Table 4, the mean score for the speed of speaking is greater in the female group $(M=205.27)$ than in the male group $(M=167.60)$. Additionally, Figure 2 illustrates this variation between male and female interpreters more clearly. 


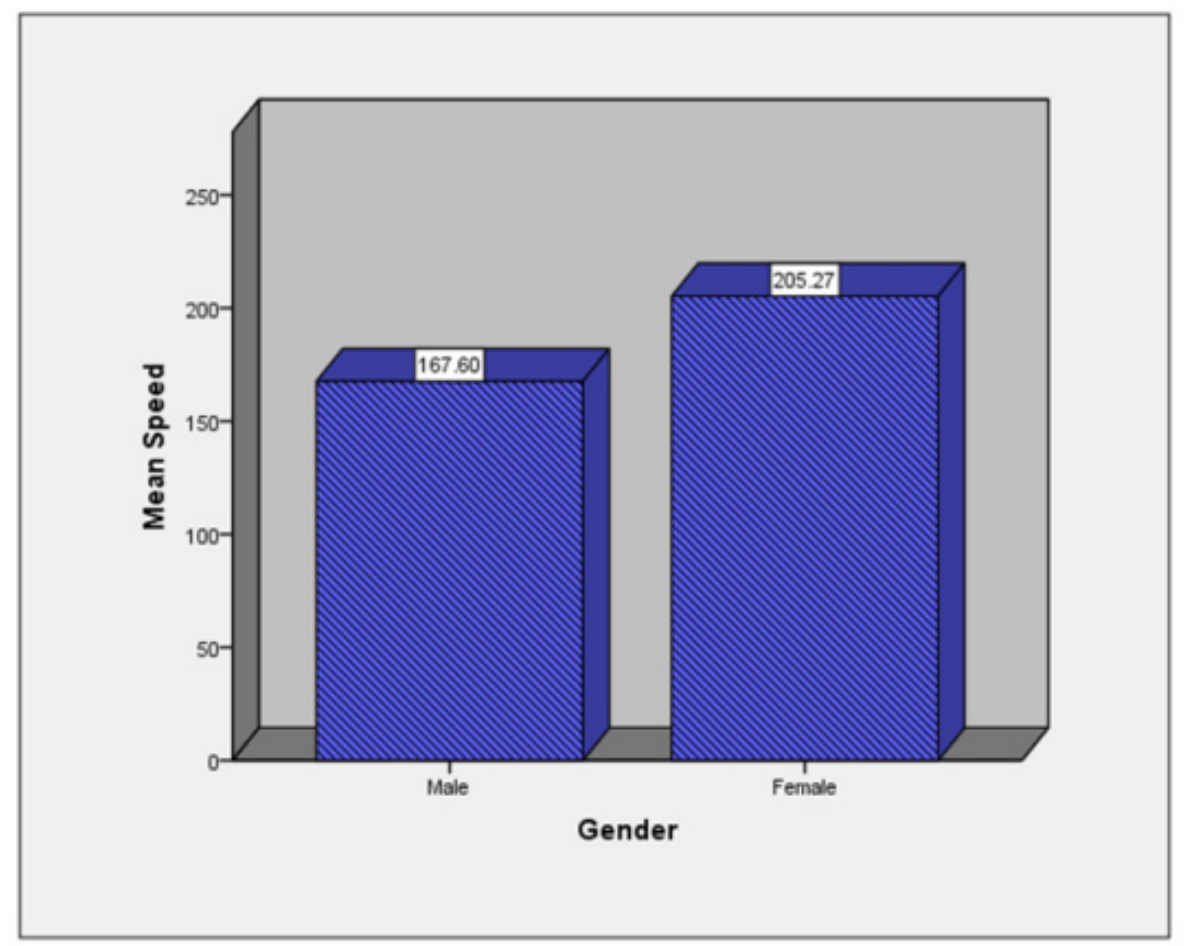

Figure 2. The speed of speaking among male and female interpreters

Nevertheless, the significance of this difference should be checked in the independent samples t-test table below.

Table 5. Independent samples t-test of the speed of speaking

\begin{tabular}{|c|c|c|c|c|c|c|c|c|c|c|}
\hline & & \multicolumn{2}{|c|}{$\begin{array}{l}\text { Levene's Test } \\
\text { for Equality of } \\
\text { Variances }\end{array}$} & \multicolumn{7}{|c|}{ t-test for Equality of Means } \\
\hline & & \multirow[t]{2}{*}{$\mathrm{F}$} & \multirow[t]{2}{*}{ Sig. } & \multirow[t]{2}{*}{$\mathrm{t}$} & \multirow[t]{2}{*}{$\mathrm{Df}$} & \multirow[t]{2}{*}{$\begin{array}{l}\text { Sig. } \\
\text { (2-tailed) }\end{array}$} & \multirow[t]{2}{*}{ Mean Difference } & \multirow[t]{2}{*}{$\begin{array}{l}\text { Std. Error } \\
\text { Difference }\end{array}$} & \multicolumn{2}{|c|}{$\begin{array}{l}95 \% \text { Confidence Interval } \\
\text { of the Difference }\end{array}$} \\
\hline & & & & & & & & & Lower & Upper \\
\hline \multirow[t]{2}{*}{ Speed } & Equal variances assumed & .218 & .644 & -3.448 & 28 & .002 & -37.667 & 10.923 & -60.042 & -15.291 \\
\hline & $\begin{array}{l}\text { Equal variances not } \\
\text { assumed }\end{array}$ & & & -3.448 & 27.998 & .002 & -37.667 & 10.923 & -60.042 & -15.291 \\
\hline
\end{tabular}

According to Table 5, the difference between male and female interpreters' speed of speaking $(t(28)=-3.448, p$ $=.002$, two-tailed) is statistically significant. Therefore, the mean score of the speed of speaking is statistically higher for the female participants than for the male ones.

Therefore, regarding the effect of gender on interpreters' speed of speaking, the study revealed that female interpreters could handle their oral productions faster compared to male interpreters. Thus, the second null hypothesis predicting that there is not any significant difference between male and female interpreters' speed of speaking in their native language is rejected.

\subsection{The Relationship between the Quality of Simultaneous Interpretation and the Speed of Speaking}

The third research question addressed the relationship between interpreters' quality of simultaneous interpretation and their speed of speaking in their native language. The following hypothesis was tested in relation to this objective of the study.

Hypothesis 3: There is not any significant relationship between interpreters' quality of simultaneous interpretation and their speed of speaking in their native language.

Pearson product-moment correlation coefficient was run on the scores of the quality of simultaneous interpretation and the speed of speaking in order to investigate the correlation between the two variables. It is worth mentioning 
that the strength of the relationship between two variables is indicated by the correlation coefficient ranging from -1.00 to 1.00 . According to Cohen (1988, pp. 79-81) "if $r=.10$ to .29 it is considered as a small correlation coefficient; if $r=.30$ to .4929 it is considered as a medium correlation coefficient; and if $r=.50$ to 1.029 it is considered as a strong correlation coefficient".

Prior to running Pearson product-moment correlation, the required analysis regarding the assumptions of linearity, homoscedasticity, and normality was done and it was made sure that the assumptions are not violated. Table 6 displays the results of the correlation coefficients.

Table 6. Pearson product-moment correlation coefficient (overall)

\begin{tabular}{llll}
\hline & Speed & Quality \\
\hline Quality & Pearson Correlation & .027 & 1 \\
& Sig. (2-tailed) & .886 & \\
Sum of Squares and Cross-products & 99.400 & 368.800 \\
Covariance & 3.428 & 12.717 \\
$\mathrm{~N}$ & 30 & 30 \\
\hline
\end{tabular}

The results of the correlation coefficient in Table 6 reveal that there is not any significant correlation between the participants' scores of the quality of simultaneous interpretation and speed of speaking $(r=.027, n=30, p=.886)$.

In order to see if there are any correlations between the two sets of scores considering each of the male and female groups separately, two other Pearson product-moment correlation coefficients were conducted for each gender group individually. The outputs of the correlation coefficients are depicted in Table 7.

Table 7. Pearson product-moment correlation coefficient for the individual male and female groups

\begin{tabular}{lllll}
\hline Gender & & Speed & Quality \\
\hline Male & Speed & Pearson Correlation & 1 & .248 \\
& & & .373 \\
& Sig. (2-tailed) & 12643.600 & 412.400 \\
& Sum of Squares and Cross-products & 903.114 & 29.457 \\
& Covariance & 15 & 15 \\
\hline & $\mathrm{N}$ & 1 & -.285 \\
& & & .303 \\
& Speed & Pearson Correlation & 12412.933 & -388.333 \\
& Sig. (2-tailed) & 886.638 & -27.738 \\
& Sum of Squares and Cross-products & 15 & 15 \\
\hline
\end{tabular}

Table 7 reports no significant correlations between the male participants' scores of the quality of simultaneous interpretation and speed of speaking $(r=.248, n=15, p=.373)$. Similarly, the results of the correlation coefficient for the female group reveal that there is not any statistically significant relationship between the subjects' quality of the interpretations and their speed of speaking $(r=-.285, n=15, p=.303)$.

All in all, based on the observed results, it can be concluded that there is no association between Iranian interpreters' quality of simultaneous interpretations and their speed of speaking in Persian. As a result, the last null hypothesis as there is not any significant relationship between interpreters' quality of simultaneous interpretation and their speed of speaking in their native language is confirmed.

\section{Discussion and Conclusion}

As far as the research on translation and interpreting is concerned, the opinion on the mere existence of any gender-related differences is often questioned. On the one hand, there is a group of researchers who claim that gender differences are not only existent in translation and interpreting, but also clear and evident. Some scholars go as far as to postulate the possibility of recognizing the gender of the translator/interpreter solely on the basis of the translation/interpretation product (e.g., Gumul, 2006). On the other hand, we have scholars who deny the existence of the intricacies concerning the gender aspect of the translator's/interpreter's work, claiming that there is a number of significantly more relevant factors (e.g., culture, education, etc.) which have an impact on the product (Pöchhacker \& Shlesinger, 2002). 
According to the data obtained from this study and the statistics provided, it seems that males and females participants were not significantly different with regard to their quality of simultaneous interpretation. However, the finding of our study showed that male and females participants did not hold the same with regard to their speed of speaking in their native language and it was shown that females produced faster oral production in comparison to the male interpreters. Therefore, it seems quite logic not to generalize the existence of gender-related differences in translation studies on all issues of translation and interpreting. As the results of the current study indicated gender-related differences are not observed in all issues related to translation and interpreting.

Moreover, the finding of our study showed that there is not any statistically correlation between interpreters' quality of simultaneous interpretation and their speed of speaking in their native language. That is to say, this study provided supporting evidence for the idea that people who are capable of handling their oral productions faster do not essentially come up with higher guilty interpretations on the one hand; and people who are not as fast as those with high speed speaking necessarily do not hand in lower quality interpretations on the other hand.

The results of this study also provide some implications for educating excellent interpreters. Firstly, interpretation educators and trainers should consider the finding of the current study so as not to include every characteristic as the required capabilities and experience for being a competent interpreter. The findings of the current study revealed that the speed of speaking in native language ought to not be regarded as a factor in selecting the persons who are likely to be excellent interpreters after education. Secondly, the outcomes could be employed in planning the curriculum for educating simultaneous interpreters as well; specifically that, there is a need for having some drills for increasing the simultaneous male interpreters' speed of speaking in their native language.

\section{References}

Cohen, J. W. (1988). Statistical power analysis for the behavioral sciences. Hillsadale, NJ: Lawrence Erlbaum Associates.

Dukate, A. (2007). Manipulation as a specific phenomenon in translation and interpreting. University of Latvia, Riga.

Gile, D. (1990). Basic Concepts and Models for Conference Interpretation Training. Unpublished monograph, Paris.

Gile, D. (1995). Basic Concepts and Models for Interpreter and Translator Training. Amsterdam: John Benjamins Publishing Company. http://dx.doi.org/10.1075/btl.8(1st)

Gumul, E. (2006). Explicitation in Conference Interpreting. In M. Thelen \& B. Lewandowska-Tomaszczyk (Eds.), Translation and Meaning. Part 7. Maastricht: Department of Translation and Interpreting, Maastricht School of International Communication, Zuyd University.

Hosseinzade, M. (2006). The Relationships between simultaneous interpreter's speed of speaking in Farsi and the quality of their interpreting. Faculty of science and research campus English department: University Iran.

Kalina, S. (2002). Quality in interpreting and its prerequisites: A framework for a comprehensive view. In G. Garzone \& M. Viezzi (Eds.), Interpreting in the 21st Century (pp. 121-130). Amsterdam/Philadelphia: John Benjamins. http://dx.doi.org/10.1075/btl.43.12kal

Kaye, P. (2008). Evaluating speaking. Retrieved from http://www.teachingenglish.org.uk/articles/evaluating-speaking

Kopczynsky, A. (1994). Quality in conference interpreting: some pragmatic problems. In M. Snell-Hornby, F. Pochhachker, \& K. Kaindl (Eds.), Translation studies: An interdiscipline (pp. 189-198). Amsterdam/Philadelphia: John Benjamins. http://dx.doi.org/10.1075/btl.2.24kop

Kurz, I. (2001). Conference interpreting: Quality in the ears of the user. Meta, 46(2), 394-409. http://dx.doi.org/10.7202/003364ar

Lamber, S., \& Moser-Mercer, B. (1995). Bridging the Gap: Empirical research on simultaneous interpreting. Amsterdam: John Benjamins Publishing Company.

Marrone, S. (1993). Quality, a shared objective. The interpreters'newsletter, 5, 35-41.

Morris, R. (2000). Justice in four languages or "interpreters and mistresses". Retrieved from http://aiic.net/page/238/justice-in-four-languages-or-interpreters-and-mistresses/lang/1 
Moser-Mercer, B. (1996). Quality in interpreting: Some methodological issues. The Interpreters' Newsletter, 7, 43-55.

Peer, P. (2000). The translating brain. Cerebral activation pattern during simultaneous interpreting, 294(2), 85-88.

Phelan, M. (2001). The interpreter's resource. Sydney: Multilingual Matters Ltd.

Pöchhacker, F., \& Shlesinger, M. (2002). The interpreting studies reader. London: Routledge.

Setton, R. (2002). Review of simultaneous interpretation. Simultaneous interpretation. Contextual and Translation, 7, 177-183.

Shirinzade, A. (2013). The Relationship between the simultaneous interpreters'speed of speaking in their native language and the quality of their simultaneous interpretation from English into their native language. Faculty of Translation Studies, School of Languages, Literacies and Translation: University Sains Malaysia.

\section{Copyrights}

Copyright for this article is retained by the author(s), with first publication rights granted to the journal.

This is an open-access article distributed under the terms and conditions of the Creative Commons Attribution license (http://creativecommons.org/licenses/by/3.0/). 